\title{
As atribuições do "Docente de apoio à integração" para a inclusão do estudante com deficiência na educação básica na província de Córdoba, Argentina
}

The tasks of the "Integration Support Teacher" for the inclusion of students with disabilities in basic education in the province of Cordoba, Argentina

Las atribuciones del "Docente de Apoyo a la Integración" para la inclusión de estudiantes con discapacidades en la educación básica en la provincia de Córdoba, Argentina

\section{Beatrícia da Silva Rossini Pereira}

Mestranda na Universidade da Região de Joinville, Joinville, Santa Catarina, Brasil.

beatricia_rossini@yahoo.com.br

ORCID - https://orcid.org/0000-0002-6326-7883

\section{Aliciene Fusca Machado Cordeiro}

Professora doutora na Universidade da Região de Joinville, Joinville, Santa Catarina, Brasil.

aliciene_machado@hotmail.com

ORCID - https://orcid.org/0000-0001-6778-5285

Recebido em 04 de dezembro de 2019

Aprovado em 30 de julho de 2020

Publicado em 30 de setembro de 2020

\section{RESUMO}

Este artigo refere-se a um estudo desenvolvido no Programa de Mestrado em Educação, da Universidade da Região de Joinville - UNIVILLE, com o objetivo de analisar como ocorre o trabalho docente na educação básica, considerando a educação especial, na província de Córdoba, Argentina. Participaram da pesquisa duas técnicas da educação especial do Ministério da Educação de Córdoba e duas docentes da modalidade de educação especial, todas da Província de Córdoba. Os procedimentos metodológicos incluíram a pesquisa bibliográfica e documental, entrevista semiestruturada e questionário on-line com perguntas abertas e fechadas. Os resultados revelam que as participantes possuem formação específica na área de educação especial, com atuação tanto na escola especial quanto na escola comum. Entre suas atribuições estão a atenção, assessoramento e orientação, a capacitação aos professores e familiares, bem como o trabalho conjunto com o professor da escola comum como apoio na integração dos estudantes com deficiência. Destacam-se, também, as condições de trabalho asseguradas legalmente e a realidade apontada pelas docentes em sua prática. $O$ trabalho colaborativo com o docente da escola comum e a responsabilização de todos os atores no processo de integração são pontos relevantes e enfatizados tanto na fala dos docentes quanto na legislação vigente.

Palavras-chave: Educação Especial; trabalho docente; Argentina. 


\section{ABSTRACT}

This article refers to a study developed at the Master's Program in Education of the University of the Joinville Region - UNIVILLE, aiming to analyze how the teaching work in basic education is developed, considering the special education in the province of Córdoba. Two special education technicians from the Ministry of Education of Córdoba and two special education teachers, all from Córdoba Province, participated in the research. Methodological procedures included bibliographic and documentary research, semistructured interview and online questionnaire with open and closed questions. The results show that the participants have specific training in the special education area, working in both special and regular schools. Its duties include attention, counseling and guidance, training for teachers and family members, as well as working together with the teacher of the common school to support the integration of students with disabilities. Also noteworthy are the legally guaranteed working conditions and the reality pointed out by teachers in their practice. The collaborative work with the common school teacher and the accountability of all actors in the integration process are relevant points and emphasized both in the teachers' speech and in the current legislation.

Keywords: Special Education; teaching work; Argentina.

\section{RESUMEN}

Este artículo hace referencia a un estudio desarrollado en el Programa de Maestría en Educación de la Universidad de la Región de Joinville - UNIVILLE, con el objetivo de analizar cómo se desarrolla el trabajo docente en educación básica, considerando la educación especial en la provincia de Córdoba. Dos técnicos de educación especial del Ministerio de Educación de Córdoba y dos maestros de educación especial, todos de la provincia de Córdoba, participaron en la investigación. Los procedimientos metodológicos incluyeron investigación bibliográfica y documental, entrevista semiestructurada y cuestionario en línea con preguntas abiertas y cerradas. Los resultados muestran que los participantes tienen capacitación específica en el área de educación especial, trabajando en escuelas especiales y regulares. Entre sus deberes están la atención, el asesoramiento y la orientación, la capacitación para maestros y miembros de la familia, así como trabajar con el maestro de la escuela común para apoyar la integración de los estudiantes con discapacidades. También son dignas de mención las condiciones de trabajo legalmente garantizadas y la realidad señalada por los docentes en su práctica. El trabajo colaborativo con el maestro de escuela común y la responsabilidad de todos los actores en el proceso de integración son puntos relevantes y enfatizados tanto en el discurso de los maestros como en la legislación actual.

Palabras clave: Educación Especial; trabajo docente; Argentina.

\section{Introdução}

Desde a década de 1990, tendo como referência os documentos elaborados nas conferências mundiais (JOMTIEN, 1990; SALAMANCA, 1994), o conceito de educação inclusiva cada vez mais desponta como orientador às práticas educacionais no Brasil e no mundo. 
http://dx.doi.org/10.5902/1984686X41420

Políticas públicas foram elaboradas a partir dessa perspectiva, tendo como meta uma educação obrigatória, laica, gratuita e equitativa, buscando garantir o acesso à educação para todos.

Essas conferências exigem de seus signatários ações planejadas e direcionadas para a resolução do que se aponta como um problema ou uma demanda social comum. Mediante isso, cada país elabora suas políticas públicas de acordo com seu contexto histórico, cultural, social e econômico.

Nesse sentido, ao tratar da organização da educação básica na Argentina, constatase que se inicia aos quatro anos de idade e finaliza no nível da educação secundária, voltada para adolescentes e jovens que tenham concluído a educação primária, perfazendo um total de catorze anos de escolarização obrigatória. Nesse contexto, é assegurado pelo Estado Nacional, através da Lei de Educação Nacional (LEN) nํ26.206, de 14 de dezembro de 2006, o direito à educação a todos os cidadãos argentinos.

No tocante à educação especial, esta constitui-se em uma modalidade de ensino que visa garantir o direito à educação de todos os estudantes com deficiência, em todos os níveis e modalidades. A LEN, em seu Capítulo II, que trata das finalidades e objetivos da política educativa nacional, traz no seu artigo 11, inciso "n”, um objetivo voltado à educação especial, que visa "oferecer às pessoas com deficiência, temporárias ou permanentes, uma proposta pedagógica que lhes permita desenvolver suas possibilidades, a integração e o pleno exercício de seus direitos" (ARGENTINA, 2006, tradução nossa).

Com o propósito de assegurar o direito à educação e inserção dos estudantes com deficiência na educação básica, a legislação vigente dispõe das medidas necessárias para assegurar esses direitos:

\footnotetext{
Possibilitar uma trajetória educativa integral com acesso a saberes tecnológicos, artísticos e culturais; b. Ter pessoal especializado trabalhando em equipes com professores da escola comum; c. Garantir a cobertura de serviços educacionais especiais (transporte, recursos técnicos e materiais para o desenvolvimento do currículo); d. Promover alternativas de continuidade para a aprendizagem ao longo da vida; e. Garantir a acessibilidade física de todos os edifícios escolares. (ARGENTINA, 2006, art. 44, tradução nossa)
}

Esses direitos, garantidos por lei, são amplamente discutidos no documento intitulado "Educação Especial, uma modalidade do sistema educativo Argentino - Orientações 1" (tradução nossa), que foi elaborado pelo Ministério da Educação em 2009, envolvendo estudiosos da educação especial, com o objetivo de sistematizar um documento reflexivo, procurando estabelecer relações entre a legislação, as políticas públicas e as práticas 
http://dx.doi.org/10.5902/1984686X41420

educativas. Esse documento reitera a importância de uma formação específica para os profissionais que trabalham com os estudantes com deficiência no sentido de "garantir" o direito à educação.

Assim, entende-se que o trabalho docente, na modalidade da educação especial, é considerado um importante instrumento para garantir o direito à educação, à aprendizagem e ao desenvolvimento das potencialidades dos estudantes com deficiência.

Nesse sentido, com a proposta de esclarecer os conceitos-chave, enfatizando a orientação dos atores ${ }^{1}$ envolvidos no processo de educação inclusiva, o documento "Orientações 1" aponta a distinção existente entre os conceitos de "inclusão" e "integração" quando citados nos documentos oficiais. A compreensão desses conceitos torna-se elemento imprescindível para o entendimento dos processos de integração dos estudantes com deficiência na Argentina.

No documento "Orientações 1", os termos "inclusão" e "integração" são definidos desta forma:

Inclusão e integração devem vincular e repensar as práticas. Então, a inclusão é princípio, processo, ação social, coletiva, que resulta de uma construção simbólica dos grupos humanos, das comunidades educativas, e contribui a melhorar as condições dos meios para acolher a todos. Propomos pensar a integração como um meio estratégico-metodológico. A integração é uma estratégia educativa que torna possível a inclusão de muitos sujeitos com deficiência na escola comum. (ARGENTINA, 2011, p. 25-26, tradução nossa).

Evidencia-se que a inclusão, assim como a educação inclusiva, abrange um público maior quando se propõe a "acolher a todos", uma vez que inclui os diversos grupos sociais, étnicos e culturais. Dessa forma, entende-se que incluir significa considerar as diferenças, de maneira que se permita o acesso à educação em condições equitativas a todos e todas.

Sendo assim, divergindo do que comumente entende-se pelo conceito de integração no Brasil, na Argentina esse termo é visto e utilizado como estratégia educativa, trazendo consigo a possibilidade de articulação entre os diversos atores da escola especial e da escola comum, com maior possibilidade de intercâmbios de saberes específicos para a efetivação da chamada inclusão educativa.

Como complementa Padin (2013, p. 52, tradução nossa), "a integração, desde que começa a ser planejada, deve ter um caráter flexível e plausível de ser submetida à análise de seus efeitos, projetando a progressiva intervenção integradora para práticas inclusivas". Dessa forma, o trabalho corresponsável, o acompanhamento sistemático e a avaliação do processo podem produzir resultados educacionais satisfatórios. 
http://dx.doi.org/10.5902/1984686X41420

Ante o exposto, este estudo propõe-se a entender como é estabelecido o trabalho docente na educação básica, considerando a educação especial, e de que maneira acontece $\mathrm{O}$ atendimento ao estudante com deficiência na Argentina, originando possibilidades de novas reflexões, sem buscar comparações imediatas com o Brasil.

\section{Metodologia}

Para consecução dos objetivos propostos, adotou-se o modelo de pesquisa bibliográfica e documental, além da utilização de entrevista semiestruturada e questionário on-line com perguntas abertas e fechadas.

Participaram da pesquisa duas técnicas da educação especial do Ministério da Educação e duas docentes da modalidade de educação especial, todas da Província de Córdoba, sendo que as técnicas responderam à entrevista e as docentes responderam ao questionário on-line.

Destaca-se que a pesquisa teve como foco a Província de Córdoba, uma vez que todos os dados foram coletados nessa província e que, diante das especificidades encontradas durante um período de imersão no país, em março de 2019, evidenciou-se que uma pesquisa de abrangência nacional traria a possibilidade de informações desencontradas e o risco de análises generalizadas, uma vez que cada província possui autonomia para legislar conforme sua especificidade, desde que fundamentada na legislação nacional.

Este estudo pauta-se na análise das principais leis nacionais e provinciais (Lei de Educação Nacional, 2006; Resolução 311, 2016; Resolução 667, 2011), nos documentos norteadores emitidos pelo Ministério da Educação relacionados à modalidade de educação especial argentina, bem como nos dados obtidos por meio das informações coletadas com os participantes.

\section{Resultados e Discussão}

\section{As configurações de apoio na modalidade de educação especial}

De acordo com os marcos legais argentinos, para haver uma trajetória educativa integral dos estudantes com deficiência, necessita-se de configurações de apoio da modalidade de educação especial.

Sendo assim, elas apresentam-se, nos documentos oficiais, como redes e interações entre pessoas, grupos ou instituições que se organizam para identificar as possíveis 
http://dx.doi.org/10.5902/1984686X41420

barreiras na aprendizagem, bem como desenvolvem estratégias educativas para participação escolar e comunitária.

Como afirma a Resolução no 311/2016, no seu Artigo 9ํ,

A intervenção da modalidade de Educação Especial implica uma abordagem institucional destinada a oferecer orientações, apoios e/ou recursos especializados às escolas de níveis obrigatórios, para criar conjuntamente as melhores condições de oportunidade para o ensino e a aprendizagem, assegurando ambientes de acessibilidade e participação. (tradução nossa).

Diante do exposto, compreende-se que a modalidade de educação especial, mediante uma abordagem institucional, destina-se a organizar o trabalho conjunto entre a escola especial e a comum, promovendo interlocuções entre ambas na busca de processos de integração dos estudantes com deficiência.

Segundo o documento "Orientações 1" (2011, p. 60-61), os apoios desenvolvem-se através de configurações práticas: atenção, assessoramento e orientação, capacitação, provisão de recursos, cooperação e colaboração, acompanhamento e investigação. No quadro a seguir, apresentam-se as finalidades de cada configuração de apoio.

Quadro 1 - Finalidades das configurações de apoio

\begin{tabular}{|c|c|}
\hline $\begin{array}{l}\text { Configuração de } \\
\text { apoio }\end{array}$ & Finalidade \\
\hline Atenção & $\begin{array}{l}\text { Avaliam-se as necessidades educativas e as barreiras de aprendizagem, para } \\
\text { tomada de decisões sobre as possíveis modificações do processo educativo. } \\
\text { Acompanha-se o processo. }\end{array}$ \\
\hline $\begin{array}{l}\text { Assessoramento e } \\
\text { orientação }\end{array}$ & $\begin{array}{l}\text { Possui caráter preventivo e tem enfoque institucional. Favorece a criação de redes } \\
\text { de comunicação, com reuniões com os envolvidos no processo, a } \\
\text { responsabilização de todos, acompanhando as ações, revisando-as e avaliando- } \\
\text { as. }\end{array}$ \\
\hline Capacitação & $\begin{array}{l}\text { Configura-se em uma atividade formativa intencional para o desenvolvimento de } \\
\text { conhecimentos e capacidades de docentes e da família. Podem ser instâncias de } \\
\text { formação e encontros pedagógicos participativos. }\end{array}$ \\
\hline Provisão de recursos & $\begin{array}{l}\text { Propõe-se a divulgação de atividades mediadoras por pessoas, grupos ou centros } \\
\text { que produzem determinados recursos e materiais para utilização nas escolas. } \\
\text { Podem ser equipamentos, meios técnicos, recursos didáticos, programas e } \\
\text { matérias curriculares, documentos, manuais, normativas, livros de consulta. }\end{array}$ \\
\hline $\begin{array}{l}\text { Cooperação e } \\
\text { colaboração }\end{array}$ & $\begin{array}{l}\text { Caracteriza-se pelo desenvolvimento de atividades conjuntamente pelos } \\
\text { integrantes do sistema de apoio e outra áreas, níveis e instituições para garantir a } \\
\text { trajetória educativa integral. }\end{array}$ \\
\hline Acompanhamento & $\begin{array}{l}\text { Implica procedimentos e o desenho da trajetória educativa integral de cada aluno } \\
\text { com a definição dos acompanhamentos necessários (planos, tempos, espaços, } \\
\text { objetivos, papéis, participantes e modos de avaliação). }\end{array}$ \\
\hline Investigação/pesquisa & $\begin{array}{l}\text { Trata-se de professores que pesquisam em espaços planejados e mediante } \\
\text { processos de reflexão. Através de análise de casos, formulam-se hipóteses, } \\
\text { confronta-se com bibliografias, sistematizando e realizando ajustes. }\end{array}$ \\
\hline
\end{tabular}

Fonte: Quadro elaborado pela própria pesquisadora com base no documento "Educação Especial, uma modalidade do Sistema Educativo na Argentina - Orientações 1”, p. 60-61 (2011). 
http://dx.doi.org/10.5902/1984686X41420

A partir disso, é importante salientar que um mesmo aluno pode receber mais de um tipo de apoio, e quem define isso é uma equipe multidisciplinar, "de modo que todos os profissionais apresentem seus conhecimentos para ter uma visão integral da criança" (ARGENTINA, 2011, p. 59, tradução nossa).

O documento "Orientações 1" afirma, ainda, que as configurações devem favorecer a seleção de estratégias apropriadas, bem como "a função da equipe está centrada em acompanhar a trajetória escolar do aluno/a e realizar trajetos flexíveis, com acompanhamento, monitoramento e avaliação do processo" (ARGENTINA, 2011, p. 59, tradução nossa).

Evidencia-se, dessa forma, que as configurações de apoio podem conter possibilidades variadas e ocorrem de acordo com as especificidades de cada aluno. Isso requer profissionais habilitados e dispostos a trabalhar em rede, com objetivos comuns e preparados para acompanhar a trajetória integral/individual de cada processo de integração, bem como condições de trabalho para que os profissionais possam desenvolver suas atribuições com qualidade.

Dentre os profissionais habilitados mencionados anteriormente, destaca-se o docente da modalidade de Educação Especial.

\section{O docente da modalidade de Educação Especial}

$\mathrm{Na}$ Argentina, o docente da modalidade de Educação Especial é um profissional que possui uma formação específica para atuar com estudantes com deficiência.

Segundo o artigo 44, letra b, da LEN (2006), é preciso "ter pessoal especializado trabalhando em equipes com professores da escola comum", e nesse contexto surge o denominado docente da modalidade de Educação Especial, que especificamente na Província de Córdoba é chamado de "docente de apoio à integração" (DAI).

Esse profissional possui formação específica na área de educação especial e está vinculado a uma escola especial. Essa formação pode ocorrer em quatro áreas distintas, conforme o documento "Recomendações para elaboração de projetos curriculares professores de Educação Especial" (2009, tradução nossa): Educação Especial com orientação em deficiência visual; Educação Especial com orientação em deficiência auditiva; Educação Especial com orientação em deficiência intelectual; e Educação Especial com orientação em deficiência Neuromotora. Ainda na Província de Córdoba, o 
http://dx.doi.org/10.5902/1984686X41420

curso de graduação em Psicopedagogia também habilita o profissional a trabalhar na área da Educação Especial.

Conforme o documento que recomenda os projetos curriculares para professores da Educação Especial, a formação inicial deve ser de no mínimo quatro anos, incluindo, entre outros aspectos, a realização de práticas desde o início do curso superior. Esse profissional possui como uma de suas principais atribuições trabalhar conjuntamente com o professor da escola comum, para promover a integração escolar dos alunos com deficiência.

Com essa configuração de formação inicial, verifica-se que os profissionais têm especialidade em determinada deficiência, o que pode contribuir para uma abordagem mais assertiva quando se pensa em estratégias pedagógicas que promovam a apropriação do conhecimento. Contudo, isso pode trazer certo rigor no que tange ao conhecimento das peculiaridades do universo escolar.

Conforme afirma Bueno (1999, p. 24),

se por um lado a educação inclusiva exige que o professor do ensino regular adquira algum tipo de especialização para fazer frente a uma população que possui características peculiares, por outro, exige que o professor de Educação Especial amplie suas perspectivas, tradicionalmente centradas nessas características.

Partindo desse pressuposto, compreende-se que, muito mais do que uma formação inicial adequada, existe a necessidade de uma formação contínua e focada nas demandas de cada espaço educativo. Essa formação torna-se imprescindível no processo de integração das pessoas com deficiência, uma vez que ela acontece nas relações em rede, agregando diferentes pessoas, saberes e vivências.

\section{O docente de apoio à integração na província de Córdoba}

$\mathrm{Na}$ Argentina, há leis gerais que têm validade em todo o território nacional e há leis provinciais que visam a responder as especificidades locais. Cada província tem autonomia para criar sua legislação atendendo às questões regionais, desde que tenha por fundamento a legislação nacional.

Desse modo, o Ministério da Educação do Governo de Córdoba criou em 2011 uma normativa, a Resolução n 667, para dispor sobre a integração como estratégia de inclusão aos estudantes que apresentam necessidades educativas derivadas da deficiência, considerando o sistema educativo provincial nos níveis e modalidades. 
http://dx.doi.org/10.5902/1984686X41420

Nessa província, diferentemente das demais províncias do país, o docente da modalidade de Educação Especial é conhecido como "Docente de apoio à integração" (DAI).

A referida resolução apresenta quem é esse profissional em seu Artigo $8^{\circ}$, quando diz que "o docente de apoio à integração será um Professor de Grau de Ensino Especial [...] dependente de uma Escola de Modalidade Especial de gestão estatal ou privada" (CÓRDOBA, 2011, tradução nossa).

Seu papel e função, de acordo com a resolução provincial, são amplos, uma vez que interagem com vários atores que compõem as redes de apoio no processo de integração dos estudantes com deficiência.

A $\mathrm{DAl}^{3}$ pode assessorar, orientar, capacitar, planejar e avaliar o processo de integração na escola através de seu trabalho conjunto com o docente da escola comum, com acompanhamento semanal ou de acordo com a demanda das escolas atendidas, com horário específico para atender cada aluno e seu respectivo docente, seja no nível inicial, primário ou secundário.

Além de cumprir a função de mediador, coordenador das ações e das relações interinstitucionais no que tange à educação especial, destacam-se, a seguir, diferentes atribuições da docente de apoio à integração em relação aos atores envolvidos no processo de integração.

Quadro 2 - Funções da Docente de apoio à integração:

\section{FUNÇÕES DA DOCENTE DE APOIO À INTEGRAÇÃO (RESOLUÇÃO 667/2011)}

Em relação à instituição - informa, sugere, orienta e coordena as ações para implementar cada trajetória escolar.

Em relação aos docentes da escola comum - assessora e acompanha o trabalho do docente e participa da elaboração das adequações curriculares segundo as características do aluno e suas possibilidades.

Em relação ao aluno - realiza uma avaliação das possibilidades do aluno e identifica as barreiras de aprendizagem, acesso e participação, implementando estratégias educativas que permitam ao aluno se desenvolver no contexto educativo e comunitário com o menor grau de dependência e maior grau de autonomia possível. Realiza o seguimento do processo de aprendizagem.

Em relação aos pais - facilita a aproximação e participação da família no processo de integração, promovendo uma abordagem integral do aluno conjuntamente com o docente de aula.

Fonte: Quadro elaborado pela própria pesquisadora, com base nas informações da Resolução 667 (2011). 
http://dx.doi.org/10.5902/1984686X41420

Mediante o cenário apresentado, entende-se que a DAl é uma profissional fundamental, pois desempenha um papel relevante no processo de integração dos estudantes com deficiência, trabalhando diretamente com os docentes da escola comum.

Porém, cabe observar que, com a quantidade de funções apresentadas à DAI relativas às suas articulações com os variados atores, pode existir uma sobrecarga, uma responsabilização exacerbada ou até mesmo individualizada no processo de integração do estudante com deficiência. Por transitar em todas as instâncias (estudante, pais, escola especial, docente da escola comum), pode haver o entendimento equivocado de que o processo de integração está por sua responsabilidade, ficando em segundo plano as mediações realizadas pelos demais atores.

\title{
A complexidade do trabalho da docente de apoio à integração na educação básica
}

Compreendendo que a DAI pode transitar por instâncias variadas, faz-se necessário elucidar que, após o ingresso do estudante com deficiência na escola comum, há o encaminhamento da DAI para essa escola, e uma das suas atribuições básicas é conhecer o estudante e observar seu entorno: a dinâmica da sala de aula, as características do grupo, o espaço físico, seu(s) professor(es), o currículo da série em que ele está inserido e o planejamento do professor, iniciando-se, dessa forma, a abordagem institucional.

Essa abordagem é elucidada na Resolução 311/2016 do CFE, no seu Artigo 9º, quando esclarece que

\begin{abstract}
A intervenção da modalidade de Educação Especial implica uma abordagem institucional destinada a oferecer orientações, apoios e/ou recursos especializados às escolas de níveis obrigatórios, para criar conjuntamente as melhores condições de oportunidade para o ensino e a aprendizagem, assegurando ambientes de acessibilidade e participação. (grifo e tradução nossa).
\end{abstract}

Observa-se que a "abordagem institucional" apresentada ratifica a função da DAI no processo de integração como uma configuração de apoio, pois enfatiza o trabalho colaborativo que será desenvolvido em parceria com o docente da escola comum, evidenciando-se a valorização do conhecimento específico que a DAI possui. Essa profissional compartilha seu conhecimento para apoiar o processo de integração, contudo, está vinculada a uma escola especial, configurando-se em um trabalho entre instituições para alcançar um objetivo comum.

O trabalho institucional entre escola especial e escola comum vai muito além do trabalho desenvolvido pela DAI, como afirma Mafalda ${ }^{4}$ : 
http://dx.doi.org/10.5902/1984686X41420

A escola especial realiza configurações de apoio que são várias [...] não se limita somente ao docente de apoio à integração, mas existem outras configurações oferecidas pela escola especial, que é assessoramento, orientação, capacitação, realizam oficinas docentes. (tradução nossa).

Nesse panorama, destaca-se a complexidade do trabalho da DAI, uma vez que, sendo uma profissional de outra instituição, precisa compreender e analisar aspectos diversificados no espaço escolar comum em que irá inserir-se. Sua observação inicia-se pelo estudante e suas possibilidades, indo para a observação das características do grupo que o inclui, o currículo da série, o espaço físico, para finalmente observar e entender o trabalho do docente que está diretamente envolvido com o estudante. Nessa observação incluem-se o planejamento, os recursos utilizados, a didática e a maneira como leciona-se.

Diante do exposto, evidencia-se que o trabalho da DAI visa a instrumentalizar, por meio do seu conhecimento específico, o docente da escola comum para que realize um trabalho efetivo com o estudante com deficiência. Esse é um trabalho que não segrega, que não retira o estudante de sala de aula, buscando outros espaços para as práticas educacionais.

Tendo em vista que instrumentalizar é muito mais do que oferecer ferramentas para o desenvolvimento do trabalho docente, Zanata (2004, p. 76) afirma que

Instrumentalizar um professor é oferecer a ele a possibilidade de repensar sobre sua prática, recriar sua ação pedagógica com fundamentação teórica. Ou seja, ele tem que ser livre para poder enfrentar diferentes situações durante toda a sua carreira profissional, de forma que tenha verdadeiros instrumentos teóricos-práticos que Ihe permitam flexibilizar o currículo sempre que necessário.

Para que isso de fato aconteça, faz-se necessário que se promova a cultura do trabalho colaborativo nos espaços escolares, possibilitando trocas de experiências e aprendizagens.

A cultura colaborativa apresenta-se como uma estratégia pedagógica eficaz, porque potencializa o compartilhamento de informações, a corresponsabilização, a produção do conhecimento, possibilitando flexibilizações curriculares e avaliações diferenciadas. Contribui, dessa forma, para a diminuição de ideias equivocadas sobre o potencial de aprendizagem e desenvolvimento dos estudantes com deficiências (SANTOS; MAKISHIMA; SILVA, 2015).

Corroborando os autores antepostos, Damiani (2008, p. 218) enfatiza que "o trabalho colaborativo entre professores apresenta potencial para enriquecer sua maneira de pensar, agir e resolver problemas, criando possibilidades de sucesso à difícil tarefa pedagógica”. 
http://dx.doi.org/10.5902/1984686X41420

Essa forma de trabalho encontra base teórica nos estudos de Vygotsky (1989), uma vez que o autor "argumenta que as atividades realizadas em grupo, de forma conjunta, oferecem enormes vantagens, que não estão disponíveis em ambientes de aprendizagem individualizada" (DAMIANI, 2008, p. 215).

Olga reforça essa premissa quando diz que

[o processo de integração] é responsabilidade de ambos. Por isso, para nossa normativa, o docente integrador é o professor da sala de aula, e o docente especial é o apoio à integração. [...] O docente integrador, o professor da educação secundária, o professor da escola primária e inicial e eu, docente de Educação Especial, sou do apoio à integração. Isso também é muito importante, porque também posiciona os outros atores responsáveis pelo trabalho conjunto, ou seja, a adequação dá-se de forma conjunta. Sempre! (tradução nossa).

Diante da conjuntura apresentada, destaca-se a responsabilidade do processo de integração do estudante com deficiência atribuído ao docente da escola comum que, possuindo um profissional especialista como apoio ao seu trabalho, pode qualificá-lo, evitando a segregação e incluindo, de fato, o estudante.

Contudo, enfatiza-se que realizar um trabalho colaborativo compondo atuações e conhecimentos é bastante complexo, já que envolve desde as condições estruturais para que isso aconteça até a comunicação e articulação de conceitos e abordagens. Dessa forma, presume-se que, para que haja um trabalho realmente em colaboração, é necessário que haja possibilidades de encontros, planejamento e formação coletiva.

Mafalda corrobora essa reflexão quando esclarece que

\begin{abstract}
É difícil para colocar em prática [...] os diretores e os supervisores já assumiram e são eles que devem dinamizar e organizar a jornada ou o dia para que isso seja possível, porque é muito difícil concordar e trabalhar conversando no corredor, no recreio. Tem que se sentar e conversar e escrever. [...] Que essas horas sejam produtivas. Que tenham um significado, objetivo. (tradução nossa).
\end{abstract}

Sendo assim, o trabalho da DAI possui, de certa forma, uma conexão com o trabalho desenvolvido pelo docente da escola comum. Dependendo da realidade na qual 0 desenvolve, pode tornar-se, ou não, realmente contributivo, uma vez que a mediação cotidiana do processo de aquisição do conhecimento científico dá-se pelo docente comum. Diante desse panorama, Santos; Makishima; Silva (2015, p. 8317) afirmam:

Cada profissional envolvido pode aprender e pode beneficiar-se dos saberes dos demais e, com isso, o beneficiário maior será sempre o estudante. Nesta parceria entre os professores do ensino regular e da educação especial nenhum profissional deve considerar-se melhor que os outros. 
http://dx.doi.org/10.5902/1984686X41420

Tal constatação evidencia que o trabalho conjunto, em uma parceria entre as instituições, por meio do trabalho dos docentes envolvidos no processo de integração, pode beneficiar de maneira significativa a inclusão e a apropriação do conhecimento pelo estudante com deficiência.

Entretanto, para que essa parceria tenha início e continuidade, torna-se necessário que se criem tempos e espaços para o planejamento conjunto, trocas de experiências e momentos de avaliação entre os atores envolvidos no processo de escolarização, uma vez que a DAI não permanece em sala de aula acompanhando o trabalho diário do docente da escola comum.

Partindo desse pressuposto, a Resolução 667/2011, no seu Artigo 7º , assegura que

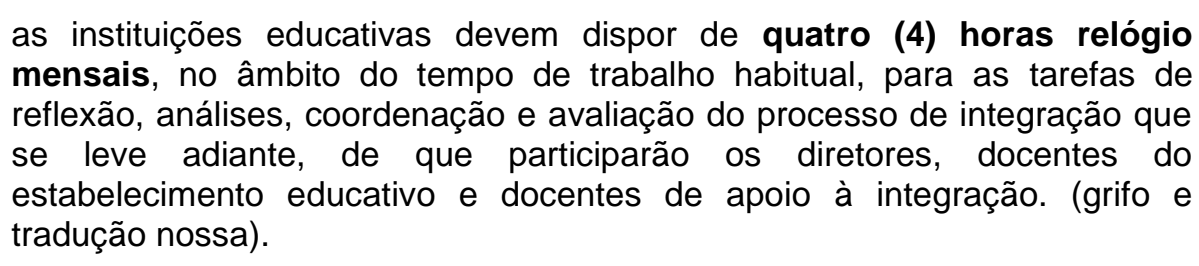

Tendo em vista que esse tempo e espaço estão garantidos na lei, infere-se que esse momento significativo realmente acontece em todas as escolas. Contudo, observa-se que existem pontos de tensão com referência a esse item quando se depara com o depoimento das participantes.

Constata-se que as formas de organização desse tempo podem variar de escola para escola, e que as quatro horas previstas na lei podem ser organizadas sob contornos variados para atender as especificidades de cada realidade.

Dessa forma, para que a carga horária seja efetivada, pode-se propiciar quatro encontros mensais, sendo uma hora por semana; ou dois encontros quinzenais de duas horas; ou ainda, como diz Olga, "uma jornada ao mês, dentro do horário de trabalho docente" (tradução nossa), uma vez que essas horas estão contempladas na carga horária de cada docente.

Esse trabalho conjunto precisa ser qualitativamente diferenciado e produtivo. As horas precisam ser bem planejadas para que se construam momentos de estudos, reflexão e avaliação do processo; para que se façam registros dos avanços e dificuldades; para que os docentes, de fato, possam (re)pensar práticas pedagógicas que promovam a aprendizagem e o desenvolvimento aos estudantes; e, finalmente, para que a DAI possa, juntamente com o docente da escola comum, sugerir adaptações curriculares, pensar 
http://dx.doi.org/10.5902/1984686X41420

novas formas de avaliação, propor estratégias pedagógicas e recursos didáticos diferenciados.

Mercedes reforça a importância desses momentos quando diz que "os espaços de reunião entre docentes de nível e docentes de educação especial (modalidade) são espaços primordiais no campo de intervenção. Essa é a forma de intervenção utilizada com maior frequência" (tradução nossa), apoiando a utilização dessa forma de trabalho conjunto no processo de integração. Assim, pode-se tirar proveito das diferenças existentes entre a formação do especialista e do generalista, canalizando-as para um objetivo comum, que é o direito de aprender do estudante.

Entretanto, se não houver esse tempo e espaço (assegurado e organizado) para o planejamento conjunto e troca de experiências, dificilmente haverá a inclusão/integração que se propõe na legislação e nos documentos norteadores.

Sob essa ótica, destaca-se o tempo dispensado a cada estudante, uma vez que cada DAI pode atender até dez estudantes por período, como delibera a Resolução 667/2011, no seu Artigo 8으,

O docente de apoio à integração será um Professor de Grau de Ensino Especial [...] dependente de uma Escola de Modalidade Especial de gestão estatal ou privada. Cumprirá suas funções atendendo um número de alunos integrados não maior que dez (10). (grifo e tradução nossa).

Contudo, essa realidade mostra-se muito complexa devido às inúmeras atribuições das DAl para atender a demanda, uma vez que transitam por diferentes escolas acompanhando o processo de integração de diversos estudantes simultaneamente.

Olga destaca que na lei estão previstos dez estudantes por DAI, mas explica que são dez estudantes por cargo/carga horária. Isso quer dizer que "se eu tenho dois cargos, posso atender vinte estudantes" (tradução nossa), compreendendo que essa carga horária equivale a vinte ou quarenta horas semanais de trabalho.

Tendo em vista que o atendimento às escolas comuns é organizado nas escolas especiais e que o número de escolas atendidas depende da área de abrangência ou zoneamento, muitas vezes uma determinada escola especial pode ter uma quantidade grande de escolas comuns para atender, sobrecarregando, dessa maneira, as DAI a elas vinculadas, como evidencia-se na fala anterior de Mercedes.

Sob essa ótica, ressalta-se, também, que a legislação procura amenizar essa realidade complexa, garantindo um complemento salarial para que se possa deslocar adequadamente, conforme destaca-se no Artigo 12ํㅜ da Resolução 667/2011: "os docentes 
http://dx.doi.org/10.5902/1984686X41420

de apoio à integração receberão um complemento salarial de acordo com o itinerário que realizam para cumprir suas obrigações" (tradução nossa).

Ao tratar da questão do transporte para os docentes, Olga relata que "nós temos, aqui em Córdoba, um programa que se chama "boleto educativo gratuito"' (tradução nossa). Sendo assim, infere-se que, mesmo que nas políticas públicas haja uma garantia financeira para que a DAI possa deslocar-se de uma escola para outra, a intensificação do trabalho docente faz-se presente, uma vez que precisa atuar em diversas escolas, com diferentes realidades e uma quantidade significativa de estudantes.

Essa intensificação do trabalho docente teve início a partir da década de $1990 \mathrm{com}$ novas políticas de regulação, desencadeando alterações significativas na dinâmica educacional da América Latina. Constata-se que a intensificação assumiu características que variam desde a questão da ampliação da jornada de trabalho, o aumento considerável das responsabilidades dos profissionais da educação, as tarefas fora do horário de trabalho (não remuneradas), até as atividades desenvolvidas durante a jornada de trabalho remunerado, o que, segundo Oliveira (2006, p. 214-215), seja

\begin{abstract}
talvez a mais preocupante, [...] caracterizando-se, portanto, em estratégias mais sutis e menos visíveis de exploração. Os trabalhadores docentes incorporam ao seu trabalho novas funções e responsabilidades, premidos pela necessidade de responder às exigências dos órgãos do sistema, bem como da comunidade.
\end{abstract}

Dessa forma, infere-se que a intensificação existe e é percebida nas vozes das participantes, uma vez que, quando questionadas sobre os desafios encontrados para a inclusão das pessoas com deficiência na escola comum, as DAl elencaram aspectos relevantes que demostram as tensões enfrentadas no trabalho que desenvolvem, mas não trazem à tona a questão do deslocamento entre as escolas, deduzindo-se que esse aspecto é assimilado com "natural", já que recebem um benefício do governo.

Todavia, Mercedes aponta para um aspecto que reflete sobre a questão da intensificação do trabalho docente quando aborda, entre os desafios encontrados, "[...] um desafio administrativo... maior quantidade de cargos docentes para DAl" (tradução nossa), demonstrando a sobrecarga de trabalho no cotidiano devido à falta de profissionais.

Dentre os desafios elencados pelas participantes, Eva evidencia que "em muitas escolas, há muita resistência à ideia de uma escola única, e muitos atores posicionados na idealização de salas de aula homogêneas. As infraestruturas não são acessíveis" (tradução 
http://dx.doi.org/10.5902/1984686X41420

nossa). Mafalda destaca que essa resistência encontra-se também em alguns atores envolvidos no processo quando afirma que

[...] todavia sabemos que também em nossas escolas, às vezes especiais, desde a equipe técnica, persiste o olhar do déficit médico, a carência [...] o que não se tem, porque no consultório terapêutico se faz isso. Focar como estudante e focar no alcance pedagógico que deve ter e ver as possibilidades de aprendizagem do estudante. É uma mudança muito grande quando começamos pelo paradigma da inclusão. (tradução nossa).

Percebe-se, nas falas precedentes, que tanto os profissionais da escola comum como os da escola especial têm dificuldade, em alguns momentos, de superar a história de segregação vivenciada durante anos por aqueles com deficiência. Considerando que existe, nas próprias escolas comuns, uma tradição hegemônica de abordar a educação de uma perspectiva homogênea, romper com essas formas de entendimento e atuação educacional pode levar muito mais tempo do que se considera o adequado.

Uma possibilidade de lidar com esse desafio é desenvolver, junto aos docentes da escola comum, por meio de formações continuadas, a reflexão sobre como propiciar aprendizagem e desenvolvimento elaborando aulas que atendam a todos os estudantes, independentemente de terem ou não deficiência. Podem ser aulas heterogêneas com utilização de recursos variados, oportunizando uma apropriação significativa e individualizada do conhecimento.

Olga esclarece que há um programa de formação permanente, no qual os docentes da escola comum e das modalidades estão envolvidos "[...] para ver se todos podemos pensar o mesmo, mas de maneira diferente" (tradução nossa), referindo-se a todos os atores compartilharem dos mesmos objetivos, focando no trabalho colaborativo e no modelo social de deficiência ${ }^{5}$ pois, como afirma, "poder ter uma linguagem comum facilita" (tradução nossa). Dessa forma, a DAI vai até a escola comum e consegue desenvolver seu trabalho, tendo ciência de que todos estão falando da mesma coisa, uma vez que participaram da mesma formação.

Sendo assim, compreende-se que a formação continuada serve de base para que o trabalho entre DAI e docente da escola comum ocorra de maneira a atingir os objetivos da Educação Inclusiva, uma vez que, 
http://dx.doi.org/10.5902/1984686X41420

Para que o trabalho colaborativo dos professores especialistas e das diferentes disciplinas ocorra com sucesso, é necessário que os profissionais envolvidos mantenham um diálogo constante, somem suas responsabilidades quanto ao processo de ensino, e após conhecer as necessidades e potencialidades do estudante, estabeleçam objetivos comuns a serem alcançados, como possibilitar o acesso e a flexibilização curricular, a avaliação diferenciada, a organização de metodologia e estratégias pedagógicas, de forma a atender às necessidades educacionais especiais dos estudantes. (SANTOS; MAKISHIMA; SILVA, 2015, p. 8323).

Dessa forma, acredita-se que, embora seja uma questão complexa e necessária, a formação continuada promove a reflexão sobre a prática, contextualização das realidades e trocas de experiências, corroborando a cultura e o trabalho colaborativo.

Contudo, Mercedes pondera que "o maior desafio está em construir a colaboração e a corresponsabilidade" (tradução nossa) e ainda afirma que "a confiança e as mudanças na educação se constroem [...] com presença e disponibilidade" (tradução nossa). Isso demonstra a fragilidade existente quando se propõe uma abordagem diferenciada. Mesmo que haja tempos e espaços para que o trabalho colaborativo concretize-se, ainda é possível observar que isso não garante sua efetivação nas práticas cotidianas.

Mediante a realidade apresentada, compreende-se que, mesmo que se deem condições de trabalho (horas de planejamento conjunto, remuneração para 0 deslocamento, formação continuada e apoios(s) ao processo de integração), ainda persiste a dificuldade em trabalhar com a diferença, em especial as diferenças significativas.

Pode-se abordar a dificuldade de lidar com a heterogeneidade dos estudantes de diferentes formas. Uma delas é a compreensão de que o professor está inserido em uma sociedade que prima pela normatização, pela rigidez e pelas relações pautadas em estereótipos. Assim, considerando que o professor é uma pessoa inteira, deve-se abordálo não só em seu aspecto técnico, mas integralmente, considerando suas vivências, sua trajetória de vida, suas crenças, sua formação inicial, seu contexto social e cultural, os quais também se refletem na sua prática.

Nóvoa (2009, p. 38) afirma que "o professor é a pessoa, e que a pessoa é o professor. Que é impossível separar as dimensões pessoais e profissionais. Que ensinamos aquilo que somos e que, naquilo que somos, se encontra muito daquilo que ensinamos".

Ante o exposto, entende-se que os desafios trazidos pela educação inclusiva reivindicam dos professores uma nova forma de olhar, de ensinar e de relacionar-se com seus estudantes e colegas de profissão. No entanto, mesmo que a formação continuada traga novas bases epistemológicas para a sua prática pedagógica, se ela não afetar a base 
http://dx.doi.org/10.5902/1984686X41420

ontológica (concepção de mundo) do professor, dificilmente haverá alguma mudança na sua prática.

Apoiando essa análise, Toledo e Martins (2009, p. 4128-4129), baseados em Marchesi (2004), destacam que

criar escolas inclusivas requer muito mais que boas intenções, declarações e documentos oficiais, requer que a sociedade, escolas e professores tomem consciência das tensões e organizem condições para criação de escolas inclusivas de qualidade.

Em meio a essa reflexão, ratifica-se a complexidade do trabalho da DAI, tendo que assessorar docentes e estudantes diferentes, em escolas com realidades diversificadas.

Sabendo que se vive em uma sociedade individualista, consumista e extremamente imediatista, incluir a diversidade e trabalhar colaborativamente apresentam-se como grandes desafios, gerando pontos de tensão que merecem análise e reflexão.

Enfim, diante de todo esse contexto que foi constituindo-se por meio das análises das atribuições, desafios e condições de trabalho da DAl, estabelecendo aproximações ao trabalho docente na modalidade de educação especial na província de Córdoba, almeja-se que, com tantas possibilidades concretas e asseguradas legalmente, possa-se valorizar ainda mais o trabalho desse profissional que está intimamente ligado à possibilidade de apropriação do conhecimento acumulado historicamente pelo estudante com deficiência na escola comum.

Sob essa ótica, anseia-se que o docente

se perceba como um agente facilitador dos processos de aprendizagem. Que ele veja cada aluno como um sujeito singular, que tem uma história própria, que traz consigo conhecimentos anteriores à vida escolar, e que se constrói através das relações sociais existentes no contexto social. (TOLEDO; MARTINS, 2009, p. 4136).

Contudo, almeja-se que se garantam condições de trabalho tanto para a DAI quanto para o docente da escola comum, para que, juntos, possam contemplar as necessidades de aprendizagem, bem como a apropriação do conhecimento aos estudantes com deficiência, para que eles não tenham apenas garantido o acesso e a permanência no sistema educativo, mas que, de fato, sejam incluídos no processo dialético de ensinar e aprender. 
http://dx.doi.org/10.5902/1984686X41420

\section{Conclusões}

Pode-se observar, pela análise da trajetória das políticas da educação especial, que a Argentina elabora leis que visam a tornar mais equitativas as possibilidades de acesso e permanência à educação de todos os seus cidadãos.

Contudo, por se viver em uma sociedade desigual e historicamente excludente, tornase difícil garantir que a equidade e a igualdade, preceitos filosóficos amplamente propagados, norteiem as práticas educacionais, mesmo que amparadas nas leis. Esse panorama reflete-se em diferentes países da América Latina pela semelhança na organização da estrutura social e econômica.

Faz-se necessário avalizar meios para que o estudante tenha acesso ao conhecimento historicamente acumulado, para que se alcance, de fato, a democratização do ensino. Essa aprendizagem muitas vezes é desconsiderada por ainda persistir, na escola, uma ótica biologicista, do defeito, da deficiência como algo inflexível e imutável, divergindo da abordagem adotada neste estudo.

Cabe considerar outro aspecto analisado, que diz respeito à formação inicial do docente da modalidade de educação especial. A formação da DAl é específica para a Educação Especial, enquanto o docente da escola comum tem formação generalista, possuindo, assim, conhecimentos distintos e, ao mesmo tempo, complementares para atuação com os estudantes.

Nesse caso, a formação continuada mostra-se como uma estratégia potente, pois promove possibilidades de reflexão teórico-práticas sobre as questões desafiadoras que a diversidade possui e, se estiver centrada em uma formação local, pode valorizar as especificidades do estudante, além das características do lugar no qual está inserido.

Outra questão destacada na pesquisa refere-se à "abordagem institucional" adotada na Argentina. Essa proposta pode promover um olhar social para a deficiência, a partir do qual as diferentes instituições podem colaborar com diferentes conhecimentos acumulados historicamente. Na medida em que as histórias dessas instituições entrelaçam-se, cria-se a possibilidade de compartilhamento de realidades distintas, reforçadas pelo trabalho colaborativo entre os docentes, podendo eles aprender e desenvolver-se.

Todavia, mesmo que apareça como uma possibilidade exitosa para o processo de integração do estudante, ainda se percebem tensões que precisam ser superadas no que tange às condições de trabalho. A quantidade reduzida de DAl e um número cada vez maior de estudantes integrados mostra-se como um grande desafio a ser vencido. 
http://dx.doi.org/10.5902/1984686X41420

Nesse aspecto, a realidade mostra-se contraditória quando se analisa o dia a dia da DAI. Mesmo que a legislação assegure um tempo para o trabalho colaborativo e o transporte gratuito, a intensificação do trabalho docente faz-se presente, já que é preciso atuar em diversas escolas, com diferentes realidades e uma quantidade significativa de estudantes.

Sendo assim, sinaliza-se que são escassas as pesquisas desenvolvidas no Brasil com foco em como desenvolve-se a educação especial em outros países da América Latina. Sabendo-se que se têm como pano de fundo características sociais e econômicas semelhantes, pode-se inferir que refletir sobre a educação especial e o trabalho docente nessa modalidade, pautada na realidade de outro país, pode trazer possibilidades profícuas de reflexão sobre a educação especial em nosso país.

\section{Referências}

ARGENTINA. Consejo Federal de Educación. Resolución CFE no 311, de 15 de dic. de 2016.

ARGENTINA. Ministerio de Educación de la Nación. Educación especial, una modalidad del sistema educativo argentino: orientaciones 1. 1a ed. Buenos Aires: Ministerio de Educación de la Nación, 2011.

ARGENTINA. Ministerio de Educación de la Nación. Ley de Educación Nacional. Ley no 26.206, de 14 de dic. de 2006.

ARGENTINA. Recomendaciones para la elaboración de diseños curriculares Profesorado de Educación Especial. 1ํㅡㄹ ed. Buenos Aires: Ministerio de Educación, 2009.

BAMPI, Luciana Neves da Silva; GUILHEM, Dirce, ALVES, Elioenai Dornelles. Modelo social: uma nova abordagem para o tema deficiência. Rev. Latino-Am. Enfermagem. Jul./Ago., 2010.

BUENO, José Geraldo Silveira. Crianças com necessidades educativas especiais, política educacional e a formação de professores: generalistas ou especialistas? Revista Brasileira de Educação Especial, Piracicaba, Editora UNIMEP, v. 3, n. 5, p. 7-26, set. 1999.

CÓRDOBA. Ministerio de Educación. Resolução no 667. Córdoba, de 17 de nov. de 2011.

DAMINANI, Magda Floriana. Entendendo o trabalho colaborativo em educação e revelando seus benefícios. Educar; Curitiba, n. 31, p. 213-230. Editora UFPR. 2008. 
GAMA, Eliza Rosa; TERRAZAN, Eduardo Adolfo. 0 trabalho docente: expectativas e interesses da pesquisa educacional nas últimas décadas no Brasil. $35^{\underline{a}}$ Reunião Anual da ANPED. Porto de Galinhas, Out. de 2012. Disponível em:

http://www.anped.org.br/sites/default/files/gt08-2393_int.pdf. Acesso em: 15 ago. 2019.

NÓVOA, António. Imagens do futuro presente. Lisboa: EDUCA, 2009.

OLIVEIRA, Dalila Andrade. Regulação educativa na América Latina: repercussões sobre a identidade dos trabalhadores docentes. Educação em Revista, Belo Horizonte, v. 44. p. 209-227. dez. 2006.

PADIN, Guadalupe. La educación especial en Argentina. Desafíos de la educación inclusiva. Revista latinoamericana de Educação inclusiva, Santiago de Chile, v. 7, n. 2, p. 47-61, Septiembre 2013 - Febrero 2014. Disponível em:

http://www.rinace.net/rlei/numeros/vol7-num2/RLEI_7,2.pdf. Acesso em: 12 jul. 2019.

SANTOS, Shirley Aparecida dos; MAKISHIMA, Edne Aparecida Claser; SILVA, Thaís Gama da. $O$ trabalho colaborativo entre o professor especialista e o professor das disciplinas - o fortalecimento das políticas públicas para educação especial no Paraná. In: Educere - Congresso Nacional de Educação, XII, Curitiba, 2015. Anais...Curitiba, 2015, p. 8312-8325.

TOLEDO, Elizabete Humai de; MARTINS, João Batista. A atuação do professor diante do processo de inclusão e as contribuições de Vygotsky. In: Educere - Congresso Nacional de Educação, IX, Curitiba, 2009. Anais...Curitiba, 2009, p. 4126-4138.

ZANATA, E. M. Práticas pedagógicas inclusivas para alunos surdos numa perspectiva colaborativa. Tese (Doutorado em Educação Especial) - Universidade Federal de São Carlos, São Carlos, 2004.

\section{Notas}

1 O termo "atores" é muito utilizado tanto nos documentos norteadores quanto na legislação vigente, responsabilizando todos os envolvidos no processo de integração do aluno com deficiência na escola comum, desde a família até os professores, passando pela equipe técnica e pedagógica.

2 O conceito de integração utilizado neste estudo está de acordo com a definição apresentada pelos documentos argentinos.

3 Para fins deste estudo, será adotado "as DAl", no gênero feminino, porque, em consonância com o que afirma Hypolito (1997), entende-se que o processo de feminização do magistério está "associado à expansão de rede escolar do ensino básico, fruto de transformações políticas, sociais, culturais e econômicas que se cristalizaram no século passado e nas primeiras décadas do século atual" (HYPOLITO, 1997, p. 48), compreendendo que esse fenômeno ocorreu na América Latina e no mundo.

${ }^{4}$ Elucida-se que as participantes da pesquisa foram identificadas pelos nomes Olga, Mafalda, Mercedes e Eva, fazendo referência/homenagem a quatro mulheres que marcaram significativamente a história argentina (com a exceção de Mafalda, que é uma personagem de histórias em quadrinhos escrita pelo cartunista argentino Quino).

${ }^{5} \mathrm{O}$ modelo social de deficiência adotado neste estudo diz que "[...] a ideia básica [...] é que a deficiência não deve ser entendida como um problema individual, mas uma questão da vida em sociedade, o que transfere a responsabilidade pelas desvantagens das limitações corporais do indivíduo para a incapacidade da sociedade em prever e se ajustar à diversidade" (BAMPI; GUILHEM; ALVES, 2010, p. 3). 
http://dx.doi.org/10.5902/1984686X41420

\section{Correspondência}

Beatrícia da Silva Rossini Pereira - Universidade da Região de Joinville, Univille, R. Paulo Malschitzki, Zona Industrial Norte, Joinville, Santa Catarina - Brasil.

CEP: 89219-710

(c) (i) (5)

4.0 International (CC BY-NC 4.0) 